\title{
Neural Control of Counter-Regulatory Events during Glucopenia in Man
}

\author{
Robert G. Brodows, F. Xavier Pi-Sunyer, and Robert G. Campbell \\ From the Endocrine-Metabolism Unit, Monroe Community Hospital, and the \\ Department of Medicine, University of Rochester School of Medicine and \\ Dentistry, Rochester, New York 14603; and the Medical Service, St. Luke's \\ Hospital Center and the Department of Medicine, Columbia University, \\ New York 10025
}

A B S T R A C T The effect of autonomic denervation on the metabolic and hormonal responses during intracellular glucopenia in man was investigated. 2-Deoxy-dglucose (2 DG), a competitive inhibitor of glucose metabolism, was administered intravenously to nine normal volunteers and to five patients, three with complete cervical cord transection (C-6) and two with idiopathic orthostatic hypotension. Before, during, and after a 20 min infusion of $2 \mathrm{DG}(50 \mathrm{mg} / \mathrm{kg})$ plasma concentrations of glucose, lactate, FFA, total catecholamines, immunoreactive insulin (IRI), human growth hormone ( $H G H)$, and cortisol were determined for periods up to $150 \mathrm{~min}$. In control subjects, the initial elevation of FFA, glucose, $\mathrm{HGH}$, and cortisol corresponded with the rise in total catecholamines, with maximal levels attained at $60 \mathrm{~min}$, lactate rose at a slower rate, reaching peak levels at 150 min; although no change in IRI was noted. In contrast, 2 DG-induced glucopenic stress in the autonomic denervated subjects was characterized by no detectable catecholamine release or significant rise in glucose, FFA, lactate, or IRI. However, $\mathrm{HGH}$ and cortisol responses in four of the five patients were of a similar or greater magnitude than controls.

These studies demonstrate that the integrity of the sympathoadrenomedullary axis is essential for the counter-regulatory response to intracellular glucopenia in man. Cortisol and $\mathrm{HGH}$ have no apparent role in these events.

Dr. Pi-Sunyer is a Senior Investigator of the New York Heart Association and Dr. Campbell is the recipient of an Academic Career Development Award from the $\mathrm{Na}$ tional Institutes of Health.

Received for publication 6 November 1972 and in revised form 16 March 1973.

\section{INTRODUCTION}

It has long been recognized that the sympathetic nervous system plays an integral role in the regulation of carbohydrate and lipid metabolism. Considerable experimental evidence has accumulated indicating that the integrity of the sympathoadrenal axis is necessary for the hyperglycemic response to acute glucopenia (1-3). However, the relative importance of adrenal medullary catecholamines in the counter-regulatory events during hypoglycemia in man has yet to be defined (4). Since spinal cord transection or adrenergic blockade in animals prevented hyperglycemia, fatty acid mobilization, and the catecholamine secretory response to glucopenia $(5,6)$, it seemed appropriate to examine, in man, the effect of spinal cord transection and adrenergic insufficiency on the counterregulatory response to acute glucose deprivation.

\section{METHODS}

Nine healthy volunteers, three female and six male, ages 19-25 yr served as control subjects. None had carbohydrate intolerance or a family history of diabetes mellitus and all were within $10 \%$ of their ideal weight (7).

Five patients, four men and one woman, with partial or complete autonomic dysfunction of various etiologies were studied. Three quadriplegic patients, S. G., R. D., and M. C., had segmental motor or sensory findings at the sixth cervical spinal cord segment and bilateral long-tract signs. Two patients, L. I. and S. C. had autonomic dysfunction as evidenced by anhidrosis and severe orthostatic hypotension unaccompanied by reflex tachycardia. All patients maintained body weight for at least 6 mo before the study, were within $10 \%$ of their ideal weight (7), and were otherwise healthy. None had a family history of diabetes mellitus; however, one patient, L. I., had chemical diabetes mellitus.

All subjects were studied in the postabsorptive state. After an initial control period, 2-deoxy- $d$-glucose (2 DG) ${ }^{1}$

\footnotetext{
${ }^{1}$ Abbreviations used in this paper: 2 DG, 2-deoxy-dglucose; HGH, human growth hormone; IRI, immunoreactive insulin.
} 


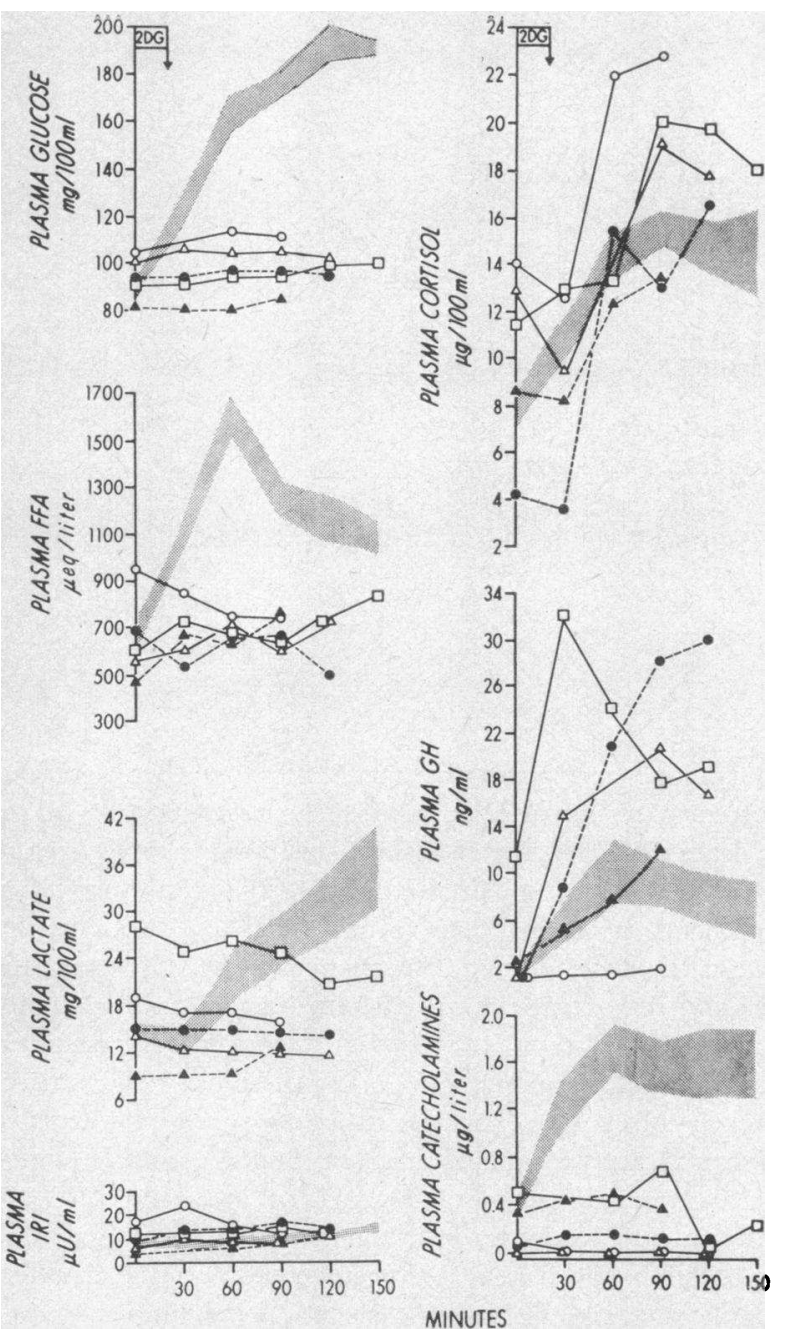

Figure 1 Patterns of metabolic and hormonal responses to $2 \mathrm{DG}$ infusion $(50 \mathrm{mg} / \mathrm{kg}$ for $20 \mathrm{~min}$ ) in nine healthy volunteers, three quadriplegic patients ( $\square$, R.D.; $\bullet$, S. G.; $\Delta$, M. C.), and two patients with idiopathic orthostatic hypotension ( $\triangle$, S. C. ; O, L. I.). Zero time values represent the mean plasma concentrations of samples obtained at -15 and $0 \mathrm{~min}$. Shaded areas indicate the mean \pm SEM for the healthy volunteers.

(50 $\mathrm{mg} / \mathrm{kg}$ ) was administered intravenously for $20 \mathrm{~min}$. Venous blood was collected during the control period and at $30,60,90,120$, and $150 \mathrm{~min}$ after the start of the $2 \mathrm{DG}$ infusion for determination of plasma glucose (8), FFA (9), lactate (10), immunoreactive insulin (IRI) (11), cortisol (12), human growth hormone (HGH) (13), and catecholamines (14).

\section{RESULTS}

The patterns of metabolic and hormonal responses to 2 DG infusion in nine healthy volunteers are indicated in Fig. 1. Plasma glucose rose progressively from a basal level of $90 \mathrm{mg} / 100 \mathrm{ml}$ to a peak of $193 \mathrm{mg} / 100 \mathrm{ml}$ at $120 \mathrm{~min}$ after the onset of $2 \mathrm{DG}$ administration. Plasma lactate concentrations increased markedly (132\% of control). Elevated levels of both glucose and lactate were sustained throughout the experimental period. There was a twofold rise in plasma FFA at $30 \mathrm{~min}$ and maximal levels of $1,613 \mu \mathrm{eq} /$ liter were attained at $60 \mathrm{~min}$. In contrast with glucose and lactate levels, FFA gradually fell toward control values during the final $90 \mathrm{~min}$ of the study. Plasma catecholamines rose significantly by 30 min, reaching a peak concentration of $1.7 \mu \mathrm{g} /$ liter at 60 min, and remained elevated for the duration of the experiment.

A significant rise in plasma $\mathrm{HGH}$ and cortisol concentrations occurred between 30 and $60 \mathrm{~min}$. Maximal levels of $\mathrm{HGH}(10.5 \pm 2.5 \mathrm{ng} / \mathrm{ml})$ and cortisol $(15 \pm 1.2$ $\mu \mathrm{g} / 100 \mathrm{ml}$ ) were observed at 60 and $90 \mathrm{~min}$, respectively (mean $\pm \mathrm{SEM}$ ). The cortisol response was sustained for periods up to $150 \mathrm{~min}$; HGH tended to fall toward baseline, but did not return to control levels.

Basal insulin levels ranged from 2.5 to $10.8 \mu \mathrm{U} / \mathrm{ml}$ with a mean of $10.4 \mu \mathrm{U} / \mathrm{ml}$. Although a slight increase in mean IRI was noted at the end of the experiment, this change was not statistically significant from control values.

The individual curves of plasma glucose, lactate, FFA, catecholamines, $\mathrm{HGH}$, cortisol, and IRI concentrations in patients with autonomic dysfunction are shown graphically in Fig. 1 and compared with the responses (mean \pm SEM) of control subjects.

In marked contrast to the response seen in normal subjects, all patients studied exhibited a striking lack of plasma glucose, lactate, FFA, and catecholamine response to $2 \mathrm{DG}$ infusion; insulin concentrations remained unchanged, as was seen in the control subjects. One quadriplegic patient, R. D., had unexplained elevated basal plasma lactate concentrations that progressively fell in the face of 2 DG stimulation.

Four of the five patients had a similar or greater $\mathrm{HGH}$ response when compared with controls. Three of these patients (S. C., S. G., and R. D.) had distinctly greater peak $\mathrm{HGH}$ levels than any single normal subject. The elderly female patient, L. I. with idiopathic orthostatic hypotension, exhibited no HGH rise. For all patients, the plasma cortisol response was comparable with that seen in the control subjects.

In two normal subjects, a comparison was made of the metabolic and hormonal responses to 2 DG with and without former administration of nicotinic acid, a specific inhibitor of catecholamine-induced lipolysis. Nicotinic acid effectively inhibited the FFA response to 2 DG, however, glucose, lactate, $\mathrm{HGH}$, insulin, and cortisol as well as catecholamine responses were not affected. 


\section{DISCUSSION}

Much of our knowledge concerning the role of the autonomic nervous system in regulating carbohydrate and lipid metabolism in man has been derived from observations of the effects of various ganglionic, and adrenergicblocking agents during glucopenic stress. However, the results of such studies are difficult to interpret since the degree of pharmacologic blockade cannot be quantitated precisely. Moreover, certain ganglionic and adrenergicblocking agents actually induce depolarization or catecholamine release (15), and local alterations in blood flow could theoretically influence various metabolic events. To avoid the difficulties inherent in the use of pharmacological blockade, patients with either anatomical disruption of the sympathetic outflow tract or with severe adrenergic dysfunction were studied during intracellular glucopenia induced by 2 DG administration. Previous studies have shown that administration of this glucose analogue is associated with fatty acid mobilization, hyperglycemia, enhanced catecholamine excretion, and growth hormone release (16). In addition, $2 \mathrm{DG}$ is an effective inhibitor of insulin release (17), and therefore, allows assessment of several metabolic parameters without the influence of concomitant changes in insulin secretion.

The degree of hyperglycemia seen in normal subjects after 2 DG infusion was similar to that observed by others (16). In contrast, blood glucose remained unchanged in all five patients with adrenergic insufficiency. The maintenance of normal glucose homeostasis in these patients suggests incomplete inhibition of glucose utilization; thus it is likely that the hyperglycemia seen in the normal subject is more directly related to the glycogenolytic effects of epinephrine rather than the direct result of 2 DG-induced inhibition of intracellular glucose metabolism.

Glucagon is also a potent stimulator of hepatic glycogenolysis (18) and 2 DG-induced glucopenia could result in enhanced glucagon secretion since insulin-induced hypoglycemia has been shown to enhance glucagon release (19). However, blood glucose remained unchanged for periods up to $150 \mathrm{~min}$ in all the patients studied. It is possible that the lack of catecholamine response may directly effect the ability to secrete glucagon (20). Alternatively, if glucagon was secreted in these patients, it did not play an important role in the acute counter-regulatory response to glucopenic stress. Finally, there is evidence that glucagon secretion is, in part, under neural control $(21,22)$ and thus disruption of neural pathways could result in inhibition of glucagon release.

Evidence exists that epinephrine, but not norepinephrine, is associated with significant increases in lactate production that is blunted after ganglionic blockade (23). In the absence of a detectable catecholamine response in the patients, there was no lactate rise, strongly implicating epinephrine as the primary stimulus for lactate mobilization.

The prompt rise in FFA, with concomitant elevations in plasma catecholamines observed in the normal subjects after 2 DG administration suggests that the enhanced lipolysis was causally related to sympathoadrenal stimulation. The effective blockade of lipolysis during glucopenia by nicotinic acid, a known inhibitor of catecholamine-induced lipolysis, in the face of elevated catecholamines, supports this concept. The lack of plasma FFA response seen in all the denervated patients indicates that neural-adrenal pathways must be intact if catecholamine-induced fatty acid mobilization is to occur during periods of acute glucose deprivation. A peripheral resistance to epinephrine in these patients is unlikely in that one patient had a normal FFA and glucose response to exogenously administered epinephrine.

The present study confirms the previously observed stimulatory effect of 2 DG administration on HGH secretion (16) and demonstrates 2 DG-induced glucopenia results in a significant and sustained cortisol secretory response. In spite of significant $\mathrm{HGH}$ and cortisol responses during glucopenia, no discernible changes in glucose or FFA were observed in the denervated patients indicating that these hormones play an insignificant role in the actue counter-regulatory response to glucopenic stress.

The study of the response to acute glucopenia in patients with various forms of sympathetic denervation has clearly demonstrated the importance of the autonomic nervous system in initiating the metabolic responses to hypoglycemia. In several animal studies, direct hypothalamic stimulation is associated with hyperglycemia (24), increased epinephrine (25), and glucagon (21) secretion. These observations suggest that stimulation of glucoreceptors in the hypothalamus leads to activation of neural pathways, which travel via sympathetic fibers, resulting in activation of hepatic glycogenolytic enzymes (26) as well as stimulation of epinephrine and glucagon secretion. The present experiments are in agreement with this hypothesis. The striking similarity in metabolic responses to 2 DG-induced glucopenia in the denervated subjects in this study and that previously observed in adrenalectomized subjects $(2,16)$, strongly implicates epinephrine as the primary hormone necessary for the glycogenolytic and lipolytic responses seen after acute hypoglycemia. The precise counter-regulatory role of glucagon and direct neural stimulation of hepatic glycogenolysis deserves further consideration. 


\section{ACKNOWLEDGMENTS}

The authors wish to thank Doctors G. J. Gibson and R. C. Griggs for referring the patients for study; Dr. D. S. Schlach for the assay of growth hormone and cortisol, and the expert technical assistance of Constance LePeter, Louyse Lee, Georgia McDonald, and Marsha Mao.

This work was supported in part by an Academic Career Development Award 5 K07 AM 70290-02 from the National Institute of Arthritis, Metabolism, and Digestive Diseases; U. S. Public Health Service Grants AM 08107 and AM 08943; General Research Support Grant RR-05403 from the General Research Support Branch, Division of Research Facilities and Resources, National Institutes of Health; U. S. Public Health Service Training Grant AM 05022, National Institute of Health, and the Nutrition Foundation, Washington, D. C.

\section{REFERENCES}

1. Altszuler, N., A. Dunn, R. Steele, J. S. Bishop, and R. C. De Bodo. 1963. Effect of 2-deoxyglucose on glucose turnover in normal and adrenalectomized dogs. $\mathrm{Am}$. J. Physiol. 204: 1008.

2. Wegienka, L. C., S. G. Grasso, and P. H. Forsham. 1966. Estimation of adrenomedullary reserve by infusion of 2-deoxy-d-glucose. J. Clin. Endocrinol. Metab. 26: 37.

3. Luft, R., and U. S. Von Euler. 1953. Two cases of postural hypotension showing a deficiency in release of nor-epinephrine and epinephrine. J. Clin. Invest. 32: 1065.

4. Wallace, J. M., and W. R. Harlan. 1965. Significance of epinephrine in insulin hypoglycemia in man. $A m . J$. Med. 38: 531 .

5. Goldfien, A., K. S. Gullixson, and G. Hargrove. 1966. Evidence for centers in the central nervous system that regulate fat mobilization in dogs. J. Lipid Res. 7: 357.

6. Hökfelt, B., and S. Bydgeman. 1961. Increased adrenaline production following administration of 2-deoxy-dglucose in the rat. Proc. Soc. Exp. Biol. Med. 106: 537.

7. 1968. Recommended Dietary Allowances: Report of the Food and Nutrition Board. National Academy of Science-National Research Council, Washington, D. C. 1968, (Publication no. 1694). 3.

8. Kadish, A. H., R. L. Litle, and J. C. Sternberg. 1968. A new and rapid method for the determination of glucose by measurement of rate of oxygen consumption. Clin. Chem. $14: 116$.

9. Trout, D. L., E. H. Estes, Jr., and S. J. Friedberg. 1960. Titration of free fatty acids in plasma: a study of current methods and a new modification. J. Lipid Res. 1: 199.

10. Hochella, N. J., and S. Weinhouse. 1965. Automated lactic acid determination in serum and tissue extracts. Anal. Biochem. 10: 304.

11. Morgan, C. R., and A. Lazarus. 1963. Immunoassay of insulin: two antibody system: plasma insulin levels of normal, subdiabetic and diabetic rats. Diabetes. 12: 115 .
12. Murphy, B. E. P. 1967. Some studies of the proteinbinding of steroids and their application to the routine micro and ultramicro measurement of various steroids in body fluids by competitive protein-binding radioassay. J. Clin. Endocrinol. Metab. $27: 973$.

13. Schalch, D. S., and M. L. Parker. 1964. A sensitive double antibody immunoassay for human growth hormone in plasma. Nature (Lond.). 203: 1141.

14. McCullough, H. 1968. Semi-automated method for the differential determination of plasma catecholamines. J. Clin. Pathol. (Lond.). 21: 759.

15. Carlson, L. A., and P. R. Bally. 1965. Inhibition of lipid mobilization. Handb. Physiol. (Sect. 5). 557.

16. Grasso, S. G., J. H. Karam, L. C. Wegienka, G. M. Grodsky, and P. H. Forsham. 1968. Use of 2-deoxy-dglucose in studying the mechanism of lipid mobilization. J. Clin. Endocrinol. Metab. $28: 535$.

17. Goldsmith, S. J., R. S. Yalow, and S. A. Berson. 1970. Effects of 2-deoxy-d-glucose on insulin-secretory responses to intravenous glucose, glucagon, tolbutamide and arginine in man. Diabetes. 19: 453.

18. Sutherland, E. W., G. A. Robison, and R. W. Butcher. 1968. Some aspects of the biological role of adenosine 3',5'-monophosphate (cyclic AMP). Circulation. 37: 279.

19. Unger, R. H., A. M. Eisentraut, M. S. McCall, and L. L. Madison. 1962. Measurements of endogenous glucagon in plasma and the influence of blood glucose concentration upon its secretion J. Clin. Invest. 41: 682 .

20. Gerich, J. E., J. H. Karam, and P. H. Forsham. 1972. Reciprocal adrenergic control of pancreatic alpha- and beta-cell function in man. Diabetes. 21 (Suppl. 1) : 332.

21. Frohman, L. A., and L. L. Bernardis. 1971. Effect of hypothalamic stimulation on plasma glucose, insulin, and glucagon levels. Am. J. Physiol. 221: 1596.

22. Porte, D., Jr., E. B. Marliss, L. Girardier, J. Seydoux, Y. Kanazawa, A. Renold, and J. Posternak. 1972. Neural regulation of pancreatic glucagon secretion. J. Clin. Invest. $51: 75 \mathrm{a}$. (Abstr.)

23. DiSalvo, R. J., W. L. Bloom, A. A. Brust, R. W. Ferguson, and E. B. Ferris. 1956. A comparison of the metabolic and circulatory effects of epinephrine, norepinephrine and insulin hypoglycemia with observations on the influence of autonomic blocking agents $\mathrm{J}$. Clin. Invest. $35: 568$.

24. Kokka, N., R. M. Eisenberg, J. Garcia, and R. George. 1972. Blood glucose, growth hormone, and cortisol levels after hypothalamic stimulation. Am. J. Physiol. 222: 296.

25. Redgate, E. S., and E. Gellhorn. 1953. Nature of sympatheticoadrenal discharge under conditions of excitation of central autonomic structures. Am. J. Physiol. 174: 475.

26. Shimazu, T., and A. Amakawa. 1968. Regulation of glycogen metabolism in liver by the autonomic nervous system. II. Neural control of glycogenolytic enzymes. Biochim. Biophys. Acta. 165 : 335. 